\title{
HIV/AIDS Among Middle and Older Adults in Puerto Rico
}

\author{
María del Carmen Santos-Ortiz, Hernando Mattei, Kenja Correa-Nivar, Elizabeth Pintado-Díaz \\ University of Puerto Rico, Graduate School of Public Health
}

\begin{abstract}
Of all the AIDS cases reported through March 2004 in Puerto Rico, 34.8\% were among the 40-59 age group, and 3.9\% in persons 60 years and over. This represents 38.7\% of all cases of AIDS in Puerto Rico. The percentage was higher among new AIDS cases diagnosed. Currently half of all new cases were 40 years and older. The most prevalent mode of exposure reported was related to sexual contact (heterosexual contact, male-male/bisexual sexual contact, male-male sexual contact and injection drug use). Injection drug use is identified as an important mode of exposure, particularly among males 40-59 years old. In the older generation, ignorance or the refusal to acknowledge their sexual interest and activity has resulted in a failure to adequately consider such health issues as sexually transmitted infections, including HIV in this population. Due to the increase of new AIDS cases and to the rapidly growing segment of the older adult population, middle and older adults are becoming an important group in need of HIV/AIDS prevention. With the intention of obtaining information on HIV risk factors among older adults a descriptive research was conducted. A non-probability sample of 157 men and 57 women 60 years and older from the San Juan Metropolitan Area was interviewed. The questionnaire included questions on HIV/AIDS knowledge, risk-perception, sexual practices, condom use and accessibility, HIV testing, alcohol and health and sociodemographic characteristics. The age range of the participants was 60-93 years old. The majority of respondents listed Social Security and food stamps as their primary source of income. Thirty-three percent of the male and $38.2 \%$ of the women perceived themselves as being at risk of HIV infection. Sexual relations during the last month were reported by $56.6 \%$ of the male and $13.2 \%$ of the women. They mention spouse, girl/boy friend as their usual partners; male also indicated casual partners and sex workers. The majority did not use condoms in their last sexual relation. Only $21 \%$ of males that reported sexual relations with sex worker always used condoms. Pharmacy was mentioned by the majority as the place where they obtain condoms. Forty five percent of female and 34\% of the male had been tested for HIV. Gonorrhea was the most frequent sexually transmitted infection reported by males and trichomonas vaginalis by females. We are confronting a condition that affects the present population as well as future generations of older adults. Recommendations of health promotion and health education interventions that contribute to decrease the HIV/AIDS incidence and to eliminate stereotyping, discrimination and disparities in health care services for this population are identify.
\end{abstract}

(C) 2004 Californian Journal of Health Promotion. All rights reserved.

Keywords: HIV/AIDS/STIs, middle/older adults, Puerto Rico, risk factors

\section{Introduction}

In Puerto Rico, as in the United States, the older population (60 and older) is the fastest growing group (WHO, 2002). According to the 2000 Census (U.S. Census Bureau, 2000) 15.4\% of the Puerto Rican population were 60 years and older and it is estimated that by 2020 this group will increase to 20\%. From 1980 to 2000 life expectancy at age 60 increased from 19.3 to 20.5 years for males and from 22.4 to 24.4 years for females. Given that the size of the older populations is increasing and are living longer, it is important that government and private agencies and Community Base Organizations (CBOs) provide activities that are designed to enhance optimal functioning, support healthy behaviors, prevent disease and improve the quality of life in the middle and older age population (Goulding, 2003, Ross, 2000; Takamura, 2000; WHO, 2002). 
In Puerto Rico, as in many other countries in the world, HIV\&AIDS has become a very important issue in public health. Of all the AIDS cases reported through March 2004 in Puerto Rico (28,705), 34.8\% were among the 40-59 age group, and $3.9 \%$ in person 60 years and over. This represents $38.7 \%$ of all cases of AIDS reported in Puerto Rico. (Puerto Rico Health Department, 2004)

When the time trend of new AIDS cases were analyzed, it was found that currently half of all new AIDS cases were 40 years and older at the time of diagnosis (Figure 1). From 2000-2004, new AIDS cases accounts for $33.4 \%$ in the 40 -
49 age group, $13.7 \%$ in the $50-59$ group and $5.9 \%$ in the 60 years and older. This represents $53 \%$ of all new cases diagnosed during that period of time (Puerto Rico Health Department, 2004).

When analyzing the mode of HIV exposure of all AIDS cases through March, 2004, it was found that the most prevalent type of reported risk factor for this sector of the population was related to sexual contact, (heterosexual contact, male-male/bisexual sexual contact, male-male sexual contact and injection drug use) increasing by age (Table 1 ).

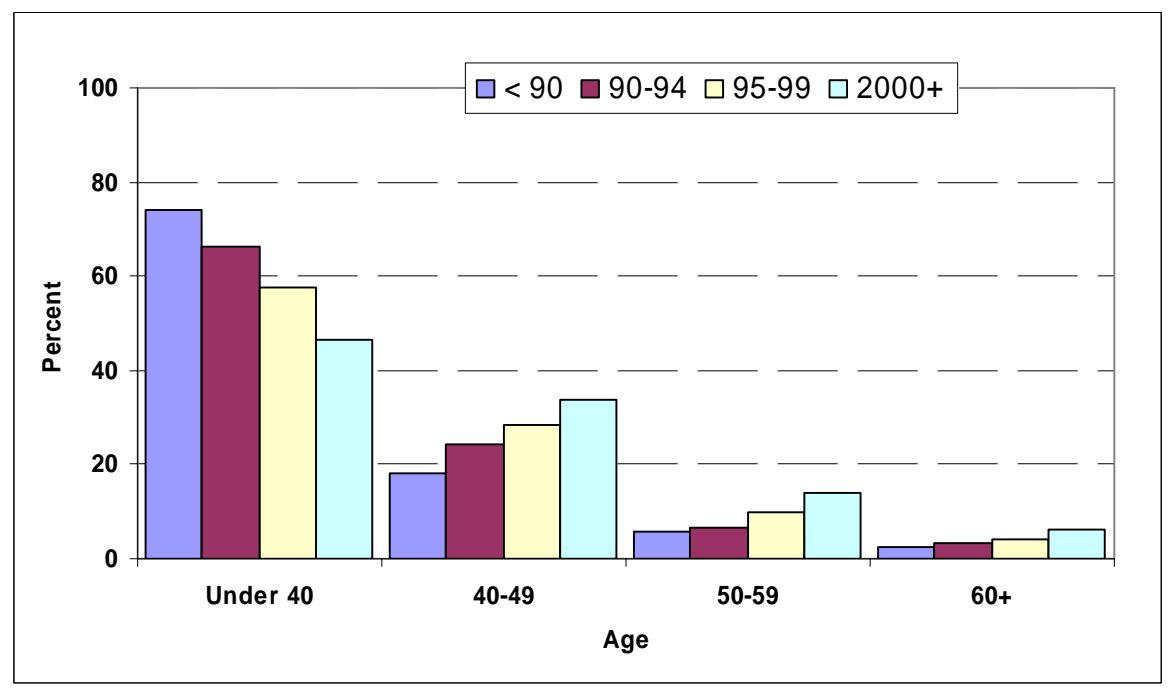

Figure 1

Percent Distribution of Age at Diagnosis of New AIDS Cases by Date of Diagnosis, Puerto Rico, 1981-2004

Table 1

Percent Distribution of Exposure Categories of AIDS Cases by Age and Sex. Puerto Rico 1981-2004

\begin{tabular}{|c|c|c|c|c|c|c|c|}
\hline \multirow{2}{*}{$\begin{array}{c}\text { Exposure } \\
\text { Categories }\end{array}$} & \multicolumn{2}{|c|}{$40-59$} & \multicolumn{2}{|c|}{$60+$} & \multicolumn{2}{|c|}{ Total } & \multirow[b]{2}{*}{ Total } \\
\hline & Male & Female & Male & Female & Male & Female & \\
\hline Homo/Bisexual & 21.0 & 0 & 25.2 & 0 & 21.4 & 0 & 17.1 \\
\hline Intravenous Drug User & 52.7 & 26.8 & 14.5 & 10.1 & 49.8 & 25.5 & 44.9 \\
\hline Heterosexual & 17.1 & 68.8 & 51.7 & 80.5 & 19.8 & 69.7 & 29.9 \\
\hline Intravenous / Homo & 7.5 & 0 & 3.2 & 0 & 7.1 & 0 & 5.7 \\
\hline $\begin{array}{l}\text { Other (Hemph/tranfu/ } \\
\text { trpl/ Risk nt specf) }\end{array}$ & 1.6 & 4.3 & 5.4 & 9.5 & 1.9 & 4.7 & 2.5 \\
\hline
\end{tabular}


A gender difference in relation to exposure categories was also found. AIDS cases among women 40 years and over were mostly due to heterosexual contact (40-49 years: 65.8\%; 50-59 years: $77.4 \%$; $60-69$ years: $80.5 \%$; $70-79$ years; 81.8\%; 80-89 years: 28.5\%). When comparing males, cases reported among 40-49 age group were primarily due to injections drug use (57.9\%) while sexual contact accounts for $40.8 \%$ of all cases (male-male/ bisexual contact: $19.7 \%$; heterosexual contact: $13.1 \%$; male-male contact and injection drug use: $8 \%$. In the 50-59 age category, injection drug use account for $36.5 \%$ while sexual contact account for $61.1 \%$ (heterosexual contact: 29.9\%; male-male/ bisexual contact: $25.6 \%$; male-male contact and injection drug use: $5.6 \%$ ).

Heterosexual contact becomes the primary mode of exposure to HIV among men 60 years and over (60-69 years: 51.6\%; 70-79 years: $63.8 \%$; 80-89 years: $80 \%$; $90-99$ years: $100 \%$ ). Malemale/bisexual sexual contact was mentioned as the HIV risk factor in $25.2 \%$ of the $60-69$ years old group; $17.1 \%$ of the $70-79$ years old; $11.4 \%$ of the 80-89 years old. Male-male sexual contact and injection drug use was identified by $3.2 \%$ of the $60-69$ years old group; $1.9 \%$ of the 70-79 years old. It's is important to mention that even though the injection drug use risk factor decreases with age; it accounts for $47.5 \%$ of all AIDS cases in the 40-59 age range and $12 \%$ for the 60 years old and over group.

Despite this information, preventive efforts for HIV transmission among these groups have been difficult and almost non-existent, especially among older adults. In Puerto Rico's society, as in many others, sexual practices are considered a private matter operating within narrow boundaries of acceptable expression. In the older generation, ignorance or the refusal to acknowledge their sexual interest and activity has resulted in a failure to adequately consider such health issues as sexually transmitted infections including HIV (Goodroad, 2003; Office of Minority Health, 2002). These ideas have been identified as one of the more prevalent form of prejudice, discrimination and inequality of preventive efforts directed to older adults in society.

Many health and behavioral professionals subscribe to society's stereotypes of older people as being sexually inactive, therefore, they do not ask about their sexual practices or provide them information about prevention of HIV and other STI's. This same stereotyping also prevents older adults, who may feel they are not supposed to engage in sexual activity, from telling health professionals and caregivers about their behavior or asking for information.

Older-aged bisexual, gay men and lesbians, who may not have openly expressed their sexual orientation, may be particularly reluctant to look for sexual health information or care services. Not all older people who are sexually active are in marriages or other longstanding monogamous relationships, and not all have been active only with their spouses or regular sexual partners. In addition, older people usually do not use condoms because pregnancy is no longer a concern or they do not perceive themselves at risk for STI's or HIV.

Several efforts have been made to recognize sexual rights and responsible sexual behavior as an important component in sexual health promotion among sexually active persons, including the older adult population (Office of the Surgeon General, 2001; World Health Organization, Pan American Health Organization, World Association of Sexology, 2000).

To obtain further information about this aspect, we conduct a descriptive study on HIV riskperception, HIV/AIDS knowledge, sexual practices, preventive measures (condom use, HIV testing), health and sociodemographic aspect of older adults in Puerto Rico.

\section{Methods}

\section{Participant}

A non probabilistic sample of 157 persons (98 males, 59 female) 60 years and older were recruited in Multiple (Social and Health) Service Centers in the San Juan Metropolitan Area. Age ranges from 60 - 93 years old. Thirty-seven 
percent were between 60-69 years, 41\% being between 70-79 years, and 22\% percent eighty years and older. In relation to marital status, $77 \%$ informed being single, widowed, divorced or separated (68\% male/ $86 \%$ female). The majority reported a monthly income of $\$ 600$ or less: social security and food stamps were indicated as the main source of income. In relation to education $71.3 \%$ had less than high school, $11.5 \%$ had less than college and $17.2 \%$ were college graduates.

\section{Data Collection}

After having obtained their informed consent, information was collected from each participant by a personal interview lasting from 45 minutes to one hour. The interviews were held in different Multiple Service Centers in the San Juan Metropolitan and were conducted by experienced health professionals and trained graduate students. All of the participants were interviewed by same-sex interviewers.

\section{Results}

\section{Risk Perception}

Approximately one fourth of both females (25.9\%) and males (24.2\%) interviewed reported having felt at risk of getting HIV during their lifetime, thus the majority among both gender reported never having felt at risk of acquiring HIV. The majority (69.9\%) of older adults interviewed believe there is a high possibility of a person their age of getting infected with HIV with male (72.6\%) having higher rates than females (65.5\%). When asked is they felt at risk of getting infected at the moment of the interview, $38.2 \%$ females and $33.7 \%$ of males said yes (Table 2).

\section{Knowledge}

In general, only $46.5 \%$ of participants were found to have adequate HIV/AID knowledge, with females having higher rates (54.2\%) than males (41.8\%). Data shows that knowledge decreases with older age in general and by age. (Table 2).

The majority of those interviewed know that HIV infection can be acquired by sexual relations (92.8\%), needle sharing (89.5\%), contact with body fluid (88.8\%), blood transfusion (86.9\%) and organ transplants (74.0\%). But misconceptions or myths about HIV transmission are still prevalent among the older aged. Sixty-eight percent of the participants think that HIV can be transmitted by a mosquito bite, $61.4 \%$ sharing dining ware (i.e., plates, glasses, knives, forks, etc.), $48.3 \%$ sharing a bedroom in the hospital with an infected person, $41.9 \%$ contact with an infected co-worker, and $36.6 \%$ through casual contact.

Although $62 \%$ of those interviewed know that AIDS is a clinical condition in which the body cannot fight off other conditions, 38\% of them do not know this fact. On the other hand, 79.7\% know that HIV is not a common cold of flu like illness, but a serious condition.

Seventy-four percent (74.5\%) of the interviewees acknowledge that persons 60 years old and over are at risk of acquiring HIV infection. Seventy-five percent persons interviewed know that the condom is a preventive measure that reduces the risk of HIV transmission. The majority $(55.6 \%)$ think that HIV can be cured if treated early.

\section{Partner}

Fifteen percent of females and $32.7 \%$ of the male participants indicated having a partner at the moment of the interview. Of those, $87.5 \%$ of the female and $76.9 \%$ of the male indicated spouse, boy/girl friend as their partners. Thirteen percent of the female and $7.7 \%$ of the males indicated a friend as their partners. Male also identified casual partners and sex workers as sexual partners.

\section{Sexual Practices}

Fifty-six percent of the male and $13.2 \%$ of the female participants indicated having sexual relations during the last month. Of those, 58.9\% of the male $(n=29)$ and $46.2 \%$ of the females $(n=3)$ indicated one sexual partner. Eighteen percent of the male $(n=9)$ and $53.8 \%$ of the females $(n=4)$ indicated two partners and $23.2 \%$ of the male $(n=11)$ indicated three or more sexual partners.

When asked about sexual relations anytime during lifetime, the sexual practice most 
indicated was penis-vagina intercourse. Self masturbation was mentioned by $76.7 \%$ of males and $12.7 \%$ of females. Other sexual practices (oral, anal) were also indicated by the interviewees (Table 3).

Table 2

Percentage of Respondents HIV Risk Perception and HIV/AIDS

Knowledge by Gender and Age

\begin{tabular}{|l|c|c|c|}
\hline \multicolumn{4}{|c|}{ Self perception of HIV risk } \\
\hline \multicolumn{1}{|c|}{ Age } & Male & Female & Total \\
\hline $60-69$ & 31.4 & 31.8 & 32.7 \\
\hline $70-79$ & 35.3 & 37.0 & 36.1 \\
\hline $80+$ & 34.6 & 66.7 & 40.6 \\
\hline Total & 33.7 & 38.2 & 35.8 \\
\hline \multicolumn{4}{|c|}{ Perception that older adults are at HIV risk } \\
\hline $60-69$ & 68.6 & 70.8 & 69.5 \\
\hline $70-79$ & 76.5 & 64.3 & 70.9 \\
\hline $80+$ & 73.1 & 50.0 & 68.8 \\
\hline Total & 72.6 & 65.5 & 69.9 \\
\hline \multicolumn{4}{|c|}{ Adequate HIV/AIDS knowledge } \\
\hline $60-69$ & 54.3 & 50.0 & 52.5 \\
\hline $70-79$ & 48.6 & 58.6 & 53.1 \\
\hline $80+$ & 17.9 & 50.0 & 23.5 \\
\hline Total & 41.8 & 54.2 & 46.5 \\
\hline
\end{tabular}

Table 3

Percentage of Sexual Practices During Lifetime Among Male and Female Older Adults

\begin{tabular}{|l|c|c|}
\hline Sexual Practices & $\begin{array}{c}\text { Male } \\
(\mathbf{n = 9 1 )}\end{array}$ & $\begin{array}{c}\text { Female } \\
(\mathbf{n = 5 6 )}\end{array}$ \\
\hline Penis-vagina & 96.7 & 100 \\
\hline Oral-Penis & & \\
\hline Receiver & 38.6 & 0 \\
\hline Giver & 0 & 8.2 \\
\hline Oral-Vagina & & \\
\hline Receiver & 0 & 6.3 \\
\hline Giver & 24.1 & 0 \\
\hline Oral-Anus & & \\
\hline Receiver & 1.2 & 4.1 \\
\hline Giver & 4.8 & 0 \\
\hline Anal-Penis & & \\
\hline Receiver & 4.0 & 10.2 \\
\hline Giver & 24.4 & 0 \\
\hline Self Masturbation & 76.7 & 12.7 \\
\hline
\end{tabular}




\section{Preventive Measures}

Condom Use: When having sexual relations, $84.9 \%$ of females and $70.1 \%$ of male participants indicated never using condoms. The rest of females used them mostly as a contraceptive method and males used them both as a contraceptive method and protection alternative.

In their last sexual relations, the majority of the participants did not use condom or any other alternative to protect themselves. Females did not use any protective measures, while males used them in a very low percent in penis-vagina (18.8\%), oral-penis (6\%), anal-penis/giver (5\%) and anal-penis/receiver $(25 \%, \mathrm{n}=4)$.

Only $21 \%$ of males that reported sexual relations with sex workers always used condoms. Fiftyeight percent reported never using condoms. Pharmacy was mentioned by the majority as the place where they obtain condoms.

HIV Testing: Forty-five percent of females and $34 \%$ of the male participants had been tested for HIV. Only one male indicated a positive result. Health fairs were mentioned as the most common place where they were tested.

Health: Another aspect that were explore was health perception in different areas. Fifty-four percent of female and $58.2 \%$ of male participants classified their health as excellent, very good and good during the past month.
Regular classification was mentioned by $40.7 \%$ of the female and $31.6 \%$ of the male. Eighty eight percent of the females and $68.4 \%$ of the males indicated they were very responsible with their health care during the last month. Thirty seven percent of females and males indicated they were very satisfied with their health status. Sixty one percent of females and $37.8 \%$ of the males indicated they were very satisfied with their social and recreational activities. Twenty percent of females and $14.3 \%$ of males indicated having a very good relationship with their families.

Alcohol Use: When asked about alcohol consumption during the last six months, $60 \%$ of female participant and $41.9 \%$ of male participants indicated never drinking it. Thirteen percent of males informed alcohol consumption several times weekly, and $6.9 \%$ every day. Twenty four percent of female indicated drinking alcohol on special occasions and $12.0 \%$ once a month.

Sexually Transmitted Infections: When asked if they have been diagnosed anytime with a sexually transmitted infection, the most frequent reported by males was gonorrhea $(53.8 \%)$ and by females, trichomonas vaginalis (36.8\%). Syphilis was indicated by $21.2 \%$ of the males and $15.8 \%$ of the females. Also during the last six months, $44.4 \%$ of the males were diagnosed with gonorrhea and $75 \%$ of the females with trichomonas vaginalis (Table 4).

Table 4

Percentage of Male and Female Older Adults Who Reported Having Sexually Transmitted Infections in the Last Six Months and Lifetime

\begin{tabular}{|l|r|r|r|r|}
\hline \multirow{2}{*}{$\begin{array}{c}\text { Sexually Transmitted } \\
\text { Infections }\end{array}$} & \multicolumn{2}{|c|}{ Any Time During Lifetime } & \multicolumn{2}{c|}{ Last 6 months } \\
\cline { 2 - 5 } & Male (N=98) & Female (N=59) & Male (N=7) & Female (N=40) \\
\hline Syphilis & 21.2 & 15.8 & 33.3 & 0 \\
\hline Gonorrhea & 53.8 & 5.3 & 44.4 & 0 \\
\hline Genital Herpes & 3.8 & 0 & 0 & 0 \\
\hline Venereal Warts & 0 & 10.5 & 11.1 & 25.0 \\
\hline Trichomonas vaginalis & 0 & 36.8 & 0 & 75.0 \\
\hline Scabiosis & 19.2 & 15.8 & 11.1 & 0 \\
\hline Chlamydia & 0 & 10.5 & 0 & 0 \\
\hline Hepatitis B & 1.9 & 5.3 & 0 & 0 \\
\hline
\end{tabular}




\section{Discussion}

There is no doubt that the HIV/AIDS trends among middle and older adults is changing the way we should direct our effort in prevention (Auerback, 2003; Crystal, 2003; Goulding, 2003; Goodroad, 2003; Levy, Ory, Mack, Ory, 2003). In Puerto Rico, AIDS cases are becoming more common among middle and older populations. Sexual contact and particularly heterosexual contact have become the primary HIV mode of exposure among these groups increasing with age.

When analyzing gender it was found that cases among women 40 years and over are mostly by heterosexual contact. In general women are at greatest risk than men for HIV transmission by heterosexual contact. Cultural and gender norms related to sexual expression place women and particularly older women at risk for HIV infection (Murphy, 2003). The differences between the expectations and attitudes of Latino men and women results in a double standard that visualizes men as highly sexual beings and encourages them to have more than one sexual partner. On the other hand, a "good" woman is not supposed to know about sex or enjoy it and is expected to have a passive role in heterosexual relations. In Puerto Rico, the idea of talking about sexuality may be embarrassing and not to be discussed with one's sexual partners (,Rodríguez-Díaz, 2003; Santos- Ortiz, Mendoza-Rosario). It is considered inappropriate for women to talk about STIs, HIV and safer sex, including condom use. Domestic violence is also an important issue to consider when communicating and negotiating safer sex practices. Even though the majority of cases reported in Puerto Rico occurred in women 40 years and younger, $17.1 \%$ were reported by women $40-59$ years old and $1.4 \%$ by women 60 years and older (Puerto Rico Police, 2001).

In the male population, cases reported among the 40-49 age groups were primarily due to injection drug use. In the 50-59 year old group, injection drug use was also the principal mode of exposure, but there is an increase in the heterosexual contact category. This category becomes the primary mode of exposure among men 60 years and over. Injection drug use category of exposure decrease with age, but is an important risk factor in the middle and older population in terms of preventive and treatment services.

Study results confirm that even the majority of the older adults interviewed identify a possibility of persons their age being infected with HIV, only a few identify themselves at risk. Zablostsky \& Kennedy (2003) indicated similar findings with older adults in the United States.

Knowledge is an important component in HIV prevention. Almost half of the participants were found to have adequate HIV/AIDS knowledge with females having higher percent than males, but it decreases with older age in general and by age. The majority have adequate knowledge in relation to HIV transmission. Molina-Cabrera et al. (2004) and Zablotsky \& Kennedy (2003) reported similar findings regarding sexual relations and needle sharing as modes of HIV transmission. But older persons still have misconceptions about casual contact, specifically about mosquito bite, sharing dinning ware, and casual contact with infected persons.

Sexual activities were common among older adults including different sexual practices such as vaginal intercourse, oral sex, anal sex, and masturbation. As found in Molina-Cabrera et al. (2004), sexual relations and multiple sex partners were more common among male older adults.

In relation to HIV preventive measures, it was found that the majority of the participants did not use condoms the most recent time they had had sexual relations. Females did not use any while a very low percent of males used them. Half of the males reporting sexual relations with sex workers never used condoms. Knodel, Watkins \& Van Landigham (2003) and Santos Ortiz, Lao-Meléndez and Torres-Sánchez (1999) emphasize the importance of considering male marital and extramarital sexual activity, including transactional and commercial sexual relations. In the Latino culture, men are encouraged to enjoy sexual freedom and 
extramarital sexual relationships are viewed as a sign of virility, while marital fidelity is highly valued among women.

In relation to health, the majority of the participants classified their health as excellent, very good, and good, indicating being very responsible with health care. Alcohol consumption was more common in males. When asked about sexually transmitted infections, gonorrhea was the most frequently mentioned by males and trichomonas vaginalis by females. Less than half were tested for HIV and only one person indicated being positive. Health fairs were mentioned as the place where most of them were tested. According to some authors, older persons are less likely to be tested (Mack \& Bland, 1999; Rodgers-Farmers, 1998) or don't know about testing availability (Valdiserri, Holtgrave, \& Brackbill, 1993). All of these researchers indicated that persons who were older, less educated, and had lower incomes, were less likely to know where to go for testing. Information in this area is also needed to ensure appropriate and relevant intervention to these groups (CDC, 2003).

It is important to recognize that middle and older persons are becoming important groups of the population in terms of HIV/AIDS prevention efforts. Government and community-based organizations that work with HIV/AIDS/STI's prevention should include middle and older adults in those services. Health promotion and health education interventions that contributed to decreasing the HIV/AIDS incidence and to eliminate stereotyping, discrimination and disparities in health care services for the population, should be emphasized. Sexual health must be included as part of health promotion interventions among these groups including persons with different sexual orientations. Even though heterosexual contact is identified as the primary mode of exposure, gay, bisexual and lesbian older adults are also important groups in term of health promotion and health education efforts.
A comprehensive, sensitive approach must be used when developing health services for these groups. It is important to consider characteristics and specific needs of the different age groups when designing interventions (Altschuler, Katz, Tyman, 2004; Coon, Lipman, Ory, 2003; Molina-Cabrera et al., 2003). Accessibility to prevention materials (condoms, dental dams, needle cleansing), STI testing (CDC, 2003), and alcohol and drug treatment services should be included in the prevention efforts.

Academic curriculum and in service training for health professionals must include these areas. It is essential to discuss concepts regarding sexuality in older adults and also to provide practicum in order to develop skills for effective interventions.

HIV/AIDS/STI prevention research must be culturally sensitive and appropriate for the population in which it is being carried out and also for which its findings will be applied (Auberback \& Cates, 2000; Levy, Holmes, Montoya, Whitsett, 2003; Smith; 2003). It is fundamental to include older adults in different types of research such as descriptive studies and treatment protocols.

These results confirm the importance of validating the sexual rights of this population and to promote sexual health of older populations. Prevention of sexually transmitted infections, including HIV, must occupy a prominent role in the efforts of private and public organizations that offer health services.

At the beginning of the 21st century, awareness of HIV/AIDS among older adults has grown. However, in the public health area, there is still a way to reduce social injustice, discrimination and health care disparity regarding older adults. To enhance sexual health in the middle and older adults is an essential goal within the efforts to reduce the incidence of HIV, in present and future generations. 


\section{References}

Altshuler, J., Katz, A. D., \& Tyman, M. (2004). Developing and intervening an HIV/AIDS educational curriculum for older adults. The Gerontologist, 44,121-126.

Auerbach, J. D. (2003). HIV/AIDS and aging: Intervention for older adults. Journal of Acquired Immune Deficiency Syndromes, 33 (Suppl. 2), 557-58.

Auerbach, J. D., \& Coates, T. J. (2000). HIV prevention research: Accomplishments and challenges for the third decade of AIDS. American Journal of Public Health, 90, 1029-1032.

Centers for Disease Control and Prevention (CDC). (2003). Advancing HIV prevention: New strategies for changing epidemic. MMWR, 52, 329-332.

Coon, D. W., Lipman, P. D., \& Ory, M. G. (2003). Designing effective HIV/AIDS social and behavioral interventions for the population of those ages 50 and older. Journal of Acquired Immune Deficiency Syndromes, 33 (Suppl.2), 194-205.

Goodroad, B. K. (2003). HIV and AIDS in people older than 50. A continuing concern. Journal of Gerontology Nursing, 29(4), 18-24.

Goulding, M. R. (2003). Public health and aging: Trends in aging-United States and worldwide. Journal of American Medical Association, 289, 1371-73.

Knodel, J., Watkins, S., and Vanlandingham. (2003). AIDS and older persons: An international perspective. Journal of Acquired Immune Deficiency Syndromes, 33, (Suppl. 2), 153-165.

Levy, J. A., Holmes, D., Smith, M. (2003). Conceptual and methodological issues in research on age and aging. Journal of Acquired Immune Deficiency Syndromes, 33 (Suppl. 2), 206-217.

Levy, J., Ory, M., and Crystal, S. (2003). HIV/AIDS interventions for midlife and older adults: Current status and challenges. Journal of Acquired Immune Deficiency Syndromes, 33, (Suppl.2), 559-67.

Mack, K. A., and Ory, M. G. (2003). AIDS and older Americans at the end of the twentieth century. Journal of Acquired Immune Deficiency Syndromes, 33 (Suppl. 2), 568-75.

Mack, K. A., Bland, S. D. (1999). HIV testing behaviors and attitudes regarding HIV/AIDS of adults 5064. The Gerontological Society of America, 39, 687-694.

Molina-Cabrera, J., Villanueva, K., Collazo, S., González, M., and García, T. (2004, June). Estudio para la identificación de necesidades educativas sobre VIH/SIDA en la población de edad avanzada, Puerto Rico: 2002-2003. Paper presentation at the meeting of the 1er. Encuentro de Enfermedades Crónicas de las Américas y el Caribe, San Juan, PR.

Montoya, I. D., Whitsett. (2003). New functions and challenges in HIV research among older minority populations. Journal of Acquired Inmuno Deficiency Syndromes, 33 (Suppl. 2), 218-225.

Murphy, E. M. (2003). Being born female is dangerous for your health. American Psychologist, 59 (3), 200-210.

Office of Minority Health. (2002). HIV/AIDS among older adults: A growing problem. HIV Impact, March/April 2002. Office of Minority Health, US Department of Health and Human Services.

Office of the Surgeon General. (2001). The Surgeon General’s call to action to promote sexual health and responsible sexual behavior (Brochure). Washington, DC.

OPS, OMS (2000). Promoción de la salud sexual: Recomendaciones para la acción. Acta de reunión (Sexual health promotion: Actions recommendations. Consulting meeting record). Guatemala, 19-22 Mayo de 2000. Organización Panamericana de la Salud, Organización Mundial de la Salud, Asociación Mundial de Sexología

Puerto Rico Health Department. (March 2004). AIDS cases 1981-2004 and new AIDS cases: <1990, 1990-1994; 1995-1999; 2000-2004. AIDS Surveillance Report, March 17, 2004.

Puerto Rico Police Department. (2001). Domestic violence by age and gender report. Statistic Division, Puerto Rico Police Department

Rodgers Farmer, A. Y. (1998). HIV risk factors, HIV antibody testing and AIDS knowledge among older Americans. Journal of Gerontological Social Work, 30(3/4), 133-146.

Ross, H. (2000). Growing older. Health issues for minorities. Closing the Gap, May 2000. Office of Minority Health, US Depatment of Health and Human Services. 
Santos-Ortiz, M. C., Mendoza-Rosario, D. N., \& Rodríguez-Díaz, C. (2003). Mujeres de edad avanzada y VIH/SIDA. Ciencias de la Conducta, 18(1), 122-145.

Santos-Ortiz, M., Laó-Meléndez, L., and Torres-Sánchez, A. (1999). Elderly males and HIV/AIDS: A present and future challenge. The Southwest Journal on Aging, 15(1), 37-43.

Takamura, J. C. (2000). In the new century, the future is aging. Closing the Gap, May 2000. Office of the Minority Health, US Department of Health and Human Services.

US Census Bureau. (2000). 2000 census of population general characteristics. Puerto Rico. Washington, DC: Author.

Valdiserri, R. O., Holtgrave, D. R., Bracbill, R. M. (1993). American adults knowledge of HIV testing availability, 83, 525-528.

World Health Organization (WHO). (2002). Health and aging. A discussion paper. World Health Organization, Geneva.

Zablotsky, D., and Kennedy. (2003). Risk factors and HIV transmission to midlife and older women: Knowledge, options and the initiation of safer sexual practices. Journal of Acquired Immune Deficiency Syndromes, 33(Supp1. 2), 122-130.

\author{
Author Information \\ María del Carmen Santos Ortiz, Ph.D., CHES, Professor* \\ Health Education Program \\ Department of Social Sciences \\ Graduate School of Public Health \\ University of Puerto Rico \\ PO Box 365067 \\ San Juan, Puerto Rico 00936-5067 \\ E-mail: msantos@rcm.upr.edu \\ Hernando Mattei, Ph.D. \\ Associate Professor \\ Department of Social Sciences \\ Graduate School of Public Health \\ University of Puerto Rico \\ Kenja Correa Nivar \\ Graduate Assistant \\ Department of Social Sciences \\ Graduate School of Public Health \\ University of Puerto Rico \\ Elizabeth Pintado Díaz, MD \\ Health Consultant \\ *Corresponding author
}

